\title{
Performance measurement in horizontal LSP cooperation as a field of conflict: the preventive role of collaborative processes
}

\author{
Carl Marcus Wallenburg ${ }^{1} \cdot$ Thorsten Schäffler $^{1}$
}

Received: 8 October 2015/Accepted: 4 April 2016/Published online: 18 April 2016

(c) The Author(s) 2016. This article is published with open access at Springerlink.com

\begin{abstract}
Engaging in horizontal cooperation is a prevalent strategy of logistics service providers (LSPs) to deal with the challenges they are confronted with by today's supply chain environment (e.g., complex and global supply chains, increased competition). These horizontal LSP alliances, for example, for providing a national less-thantruck-load network, are complex in nature and characterized by coopetition. This situation provides a fertile soil for conflict. The literature outlines that conflict, the experience that goals or interests are in opposition, emerges in areas of essential activities and that performance measurement is such an area. Yet, when these differences meet, they also become apparent and can potentially be eased. Against this background, we develop a theoretical model and test it with survey data from 193 horizontal LSP alliances. The results show that, in general, applying collaborative processes in the performance measurement reduces overall conflict in horizontal LSP cooperations. Further, based on resource dependency theory and social contract theory, this research identifies the power structure of the alliance as a relevant contingency factor and shows that joint action in PM is effective in reducing conflict in symmetrical power cooperations, while information sharing as less intense form of collaboration is effective in reducing conflict in asymmetrical power cooperations.
\end{abstract}

Carl Marcus Wallenburg

wallenburg@whu.edu

1 Kühne-Foundation Chair of Logistics and Services Management, WHU - Otto Beisheim School of Management, Erkrather Straße 224a, Düsseldorf, Germany
Keywords Alliance management - Logistics service provider - Performance measurement - Conflict . Collaborative processes

\section{Introduction}

Horizontal cooperation is a prevalent strategy for logistics service providers (LSPs) to deal with the extensive challenges of today's supply chain environment (e.g., complex and global supply chains, increased competition, rising requirements by customers) [1,2]. Examples are multicompany networks for less-than-truck-load transportation. Today, more than half of all small, medium, and large LSPs are engaged in at least one such horizontal alliance with one or multiple other LSPs [3]. This allows them to strengthen their competitive position through improved service scope and quality, increased productivity, and access to new markets $[1,3,4]$.

Horizontal LSP alliances are complex in nature [5] and entail various strategically relevant decisions on which opinions will widely differ. Examples include the question how to develop the scope of activities or in which way to support common activities with IT systems (e.g., whether to offer joint mobile apps at the customer interfaces). In addition, the alliances are influenced by the ambiguity of cooperation and competition often referred to as coopetition $[6,7]$, where members are simultaneously partners and potential competitors in the marketplace. Overall, this provides fertile ground for conflicts to emerge with the tendency to reduce performance [8].

In this respect, prior research has focused on differing conflict types and their outcomes (e.g., [9]), and on postmanifestation topics such as conflict management and resolution strategies (e.g., [10, 11]. It is clear that conflicts 
arise due to very different reasons (for example, "from incompatible goals, resource allocation disagreements, opportunistic behavior, knowledge imitation, and competition in downstream markets" [12, p. 291]), at different hierarchical levels and in different areas of the cooperation [13]. To complement this, our research views the areas of activities as possible source of and/or possible remedy to conflict, a domain that has been neglected in prior research. We concentrate on performance measurement (PM) as one key area of any organization and as such also of a horizontal alliance [14], and will show that the way PM is conducted strongly influences the level of conflict in a horizontal alliance.

While the first impulse may be to regard PM as a subordinate, operational activity within a horizontal alliance, $\mathrm{PM}$ also has a truly strategic nature in communicating and implementing strategies [15]. Consequently, Melnyk et al. [15] argue that PM needs to be co-created simultaneously with the strategy. Besides the operational measurement, PM not only entails the definition of metrics and targets for the cooperation [15, 16], but also establishing - and over time adapting [15] — what performance is (i.e., the objectives of the alliance) and how these objectives are going to be reached (i.e., the underlying performance drivers). All of these are fields where the potentially different goals and objectives, but also the different management approaches of the alliance members meet and clash [17]. As such, PM is an area prone to conflict, both relating to the question what to measure (e.g., speed vs. punctuality of delivery) and how to measure [18].

When such differences in opinion or interest meet in PM, they also become apparent and can potentially be eased, which, in turn, substantially lowers overall potential for tension and conflict within the alliance. In this respect, we build on the collaborative processes of joint action and information sharing, which, in general, have been identified as methods for effectively preventing the manifestation of conflicts $[19,20]$. We show that in the context of horizontal LSP alliances collaborative activities in PM can effectively offset the conflict potentials inherent to the alliance.

At the same time, extant literature emphasizes that the emergence and resolution of conflicts also relate to the specific context in which the conflicts develop [21, 22]. Here, the power structure has been identified to influence actions and perceptions in cooperating [23] and to be decisive in influencing whether conflict potential manifests itself into actual conflict [24].

This research extends prior research by outlining how the choice of the specific collaborative approach in PM needs to account for the alliance context it is going to be applied in. In order to do so, we draw upon resource dependency theory (RDT) [25] and social contract theory (SCT) [26]. Based on SCT, we conclude that collaborative processes in PM will shape the expectations of the alliance members and, through this, will-according to SCTcreate implicit social contracts [27]. Depending on the alliance context-we follow Dant and Schul [28] in distinguishing symmetrical and asymmetrical power relations-these mechanisms have the potential to create tension by running counter to the pursuit of autonomy that companies exhibit according to RDT.

Overall, this research addresses two research questions: (RQ 1) "How effective are joint action in PM and information sharing in $\mathrm{PM}$ as collaborative processes in reducing conflict in horizontal LSP alliances?" and (RQ 2) "To what extent does the effectiveness of these two collaborative processes in PM depend on the power structure inherent to the alliance?" Besides developing a conceptual model based on RDT and SCT, the contribution of this research lies in testing the corresponding hypotheses using structural equation modeling based on survey data from 193 logistics service providers (LSPs) engaged in a horizontal alliance.

\section{Conceptual framework}

\subsection{Conflict types and their outcomes}

According to the established understanding, conflicts are viewed in this research as "the experience between or among parties that their goals or interest are incompatible or in opposition" [19, p. 1224]. Inter-organizational relationships, where parties with different corporate cultures, different regions, different mindsets, and different ways of doing things interact intensively, provide fertile ground for such conflicts $[18,29]$-a situation typical for horizontal LSP alliances [3]. Further factors that create tension and almost inevitably lead to conflicts are mutual dependencies that require continuous interactions [30], different viewpoints concerning temporal aspects (i.e., short-term vs. long-term) [31], diverging goals, and, in the specific case of horizontal cooperation, competitive tension [31,32] among members.

Viewing conflict from one perspective only "can obscure important differences among different types of [...] conflict" [10, p. 213]. We agree and focus on the two most prominent established dimensions of conflict, cognitive and affective conflicts [33], as dependent variables in our research as these have been found to have differing implications [33, 34]. ${ }^{1}$

\footnotetext{
$\overline{1}$ Going back to [35], the literature sometimes views process conflict as an additional third type of conflict. Here, some authors argue that process conflict is not sufficiently distinct as it entails both taskrelated elements and person-related aspects. Further, Jehn et al. [36] show that task conflict and process conflict are highly correlated.
} 
Cognitive conflict, alternatively termed task conflict by [35], refers to disagreements between alliance members around task-related issues $[19,37]$ that revolve around the question of "how best to accomplish an organization's objectives" [33, p. 127]. Affective conflict, alternatively termed relationship conflict by [35], in contrast, focuses on personal elements and, therefore, tends to be more emotional in nature [38].

Conflict can both be functional and dysfunctional [39], and while research agrees about the dysfunctional nature of affective conflict (e.g., [9]), research on cognitive conflict has produced differing results. While most researchers suggest that cognitive conflict is generally harmful to cooperation (e.g., $[34,40]$ ), some view the effect as contingent to the routineness of the task [10, 41]. Here, the argumentation is that in complex tasks such as innovation and strategic decision-making that require out-of-the-box thinking, cognitive conflict is positive as disagreements and the associated friction create new ideas and trigger improvement of the task [10, 21, 41]. In contrast, in routine tasks that are characterized by a low level of variability and high repetitiveness [42], dissent is counterproductive as its management is time consuming and frustrating [41]. This is consistent with the empirical findings for horizontal LSP alliances, where [43] show that conflict only can be positive in the non-routine field of innovation generation, provided that functionality of conflict is high, and otherwise is negative. Knowing that conflicts heavily influence key outcomes of horizontal cooperation, it is important to understand the formation of conflicts and how they can be counteracted before they manifest themselves and show their negative sides.

\subsection{Power structure in horizontal alliances}

The literature has shown that the way in which conflict emerges and manifests itself depends on the business context of the cooperation [21,22] as this context determines how "a firm's practices, procedures and processes are shaped and constrained" [44]. One central contextual variable that affects conflict is the power structure specific to the relationship [21, 24, 28].

Within RDT, power is viewed as the complement to dependency following the rationale that a party $\mathrm{A}$ has power over a party $\mathrm{B}$ to the degree that $\mathrm{B}$ depends on $\mathrm{A}$ [45]. Correspondingly, the literature distinguishes symmetrical power relations and asymmetrical power relations [28].

Also from a SCT perspective symmetrical power relations and asymmetrical power relations differ substantially. SCT provides a legitimacy perspective where legitimization of activities within a relationship is provided or denied via social contracts $[26,46]$. These contracts are "norms, assumptions, and beliefs that [alliance members] conceive as fair and appropriate [i.e., legitimate] for parties involved in [alliance] relationships" [47, p. 67] and are embedded in any inter-firm relationship. Whenever any activities in the alliance run counter to the social contracts, this will create tension and evoke reactance by alliance members [26].

In a symmetrical power relation, the individual company depends on the cooperation to the same degree to which the cooperation depends on this individual company and its contributions [48]. In such a balanced power situation, the alliance members meet as equals $[49,50]$ and the degree of mutuality can be expected to be high as the members need each other to reach their individual as well as their joint goals [12]. With respect to RDT, this is a situation where every LSP gives up some autonomy, or as [51] put it, its "freedom to make its own decisions [...] without $[\ldots]$ regard to the demands or expectations of [...] partners," in order to secure resources necessary for its own success via alliance membership.

An asymmetrical power relation, in contrast, signifies imbalance regarding the individual company dependence on the cooperation. From the RDT perspective, it implies that some LSPs (the ones with high dependence) gave up much autonomy by entering the alliance, while other (the ones with low dependence) gave up less autonomy. This asymmetrical setup enables some parties to exert power over the other members $[32,50]$, and a more hierarchical and authoritarian behavior can be expected, reflected in aspects like unilateral decision-making [52].

\subsection{Performance measurement as a field of conflict}

One key area in an alliance, in which conflicts may arise due to its importance [12], is performance measurement (PM) [14]. While PM involves many operational aspects and may be disregarded from a strategical perspective, because it is thought to merely measure how the performance was, its true nature is fundamentally more far reaching.

First, in the process of PM, it is necessary to establish what performance is (i.e., the objectives of the alliance) and how these objectives are going to be reached (i.e., the underlying performance drivers). Here, potentially different goals and objectives of individual LSPs, but also different management approaches will meet and clash [17]. Second, PM needs to be changed over time as the internal context of cooperation changes (e.g., member companies entering or leaving the alliance), but also the external context of cooperation changes. Third, PM has a coordinating function across different functional units and helps to deal with complex and multiple institutional performance logics [53], which are likely to exist, by reducing the tension within and across the performance logics [53]. 
Fourth, through its different steps, it is an instrument to guide and control an organization [54, 55], in our case, a horizontal LSP cooperation, by prioritizing and by setting definite targets. This is not only reflected in the old saying "what gets measured gets done," but also in the corresponding research results, which emphasize that what actually is measured shapes what managers focus on and how they try to improve performance [15].

PM in an alliance has various attributes that makes it a likely source of conflicts. On a formal level, the questions about the what and how (i.e., what will be measured how) are origins of possible disagreements [18]. With respect to the what, disputes can arise when members discuss what the decisive aspects of the cooperation are (i.e., goals, objectives, and ambitions) and how they should be prioritized [56]. Subsequently, coordination is needed on target values for the corresponding performance indicators [17]. Yet, the multitude of opinions in a horizontal alliance may impede a consistent approach to PM resulting in the use of individual key performance indicators (KPIs) by the individual firms [57]. That, in turn, sows the seed for conflict as even using the same terminology for KPIs does not ensure that the alliance members actually measure and report the same things since the exact procedures to come up with values for the indicators may still vary [16, 58]. This potentially leads to situations in which members think that they are discussing the same things, but in reality talk about different things, not realizing that slight or even big differences between their understandings are present [17, 59]. A good example for this is service level, where even a seemingly straightforward indicator like OTIF (on-time-infull) may be measured differently by each involved LSP, for example, by measuring time of arrival in different manners: One may measure arrival when the truck reaches the site of the consignee, while another may measure it when the truck docks to the unloading dock at the consignee, while a third may only measure once the goods are unloaded and scanned.

Concerning the how to measure, members need to find a compatible way of actually conducting PM. Here, without a coordinated approach to measurement each company may pursue individual PM processes [59, 60]. However, splitting up actually interdependent processes creates interface problems that can lead to conflicts [21] as addressed by the decoupling principle of [61], which states that interdependent activities should be carried out "under the same authority" (p. 70). One reason is that already small deviations in measurement processes can lead to a differing basis of results which potentially triggers conflict as in subsequent steps the alliance members discuss performance results that are actually not comparable.
Both aspects mentioned (the what and the how) easily lead to dissent among the alliance members, as ultimately, PM reflects the operation model, and thus, the priorities and goals as well as the processes of the horizontal alliance [57]. PM has a central role in steering the cooperation and in understanding its context [60]. Consequently, it is focal to all members and a field of conflict where differing opinions and interests clash.

\subsection{Collaborative processes in PM for conflict prevention and reduction}

Prior conflict literature has mainly focused on post-manifestation issues of conflict, covering topics such as which conflict management techniques exist and how conflicts can be resolved or minimized (e.g., [10, 62]). Yet, this neglects that alliance members can also act much earlier. Once conflict is present, it is rather difficult to control [63] and requires considerable effort to manage and resolve [10, $43,62]$. Therefore, attention should also be put on actively countering conflict already before and during its emergence by promoting preventive instead of only reactive means $[11,40]$.

Conflict stems from tension, manifests itself because of "the failure of alliance partners to coordinate" [37, p. 157], and is triggered when interaction takes place [19]. Therefore, efforts to limit the emergence of conflict via preventive measures need to focus on points of interaction. Here, from the general conflict avoidance perspective two collaborative processes have shown to offer substantial potential [19, 20]: joint action and information sharing. Joint action in PM is an extensive form of collaboration and refers to alliance members actively coordinating their PM activities [64]. It is consistent with Kozlowski and Bell's [65] call for more collaborative mechanisms in preventing conflict, compared to merely exchanging information. Information sharing with respect to PM as a less intense form of collaboration [20] refers to sharing important information regarding the process as well as the results of PM (i.e., values attained for the performance indicators).

The pre-existing notion in the literature is that how conflict emerges and manifests itself depends on the business context of the cooperation and that collaborative processes in PM are effective in reducing conflict. Based on this general understanding, we develop a specific theoretical model that outlines that this effect is contingent on the (a)symmetry of power within the cooperation, and that joint action is an effective approach in symmetrical power relations, while information sharing is effective in asymmetrical power relations. The corresponding conceptual model is displayed in Fig. 1. 
Fig. 1 Conceptual model

\subsection{Context-dependent effectiveness of joint action in PM}

Joint action can be understood as interpenetration of organizational boundaries by carrying out important activities (as in this case PM) in a cooperative or coordinated way and is a key element of relational governance [51]. It aims at involving all alliance members in the PM and for them to share their needs, concerns, and expectations [66] so that they effectively become "business partners" [51, 67]. The approach promotes an atmosphere of forbearance, mutual respect, and balanced reciprocity, and reduces ex-post transaction costs [5]. Joint action in PM reflects the argument of [22] that elements which "increase the strength of the ties between groups" (p. 522) help to prevent conflicts.

\subsubsection{Symmetrical power alliances}

In symmetrical power alliances, members are reciprocally dependent and must give and take to achieve individual and mutual benefit. From the RDT perspective, this implies that all of them have given up comparable levels of autonomy. Consequently, increasing the strength of ties via joint action and extending the coordination within the alliance does not impose additional constraints to them.

Following SCT, these alliances are shaped by expectations that are reflected in "norms based in informal social contracts," which "essentially frame their relationship" [26, p. 29]. One such key expectation in symmetrical power alliances is that members have equal say in terms of

\section{Context dependency}

Power structure (symmetrical vs. asymmetrical)
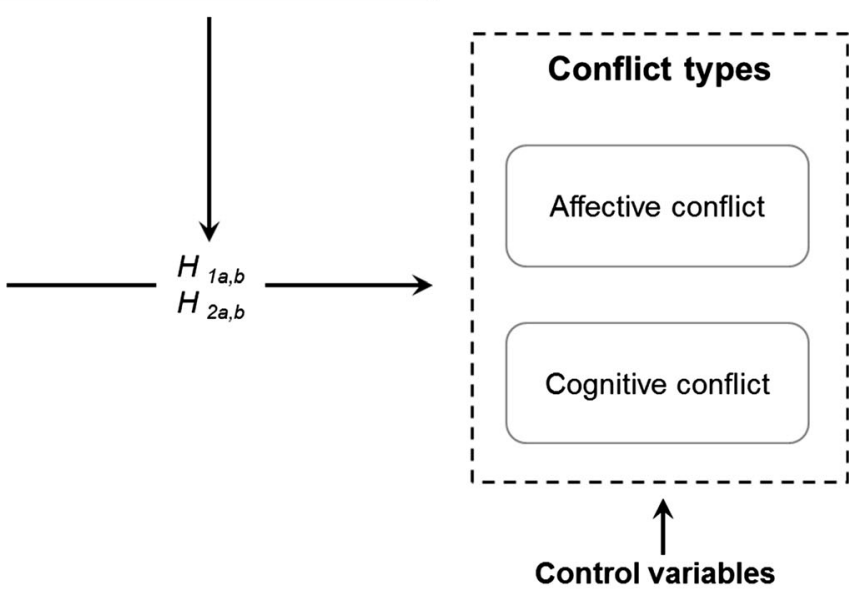

Cooperation size, relationship duration

decisions made and processes conducted. The involvement in PM processes creates a platform to pursue this claim as it provides the opportunity to express possible concerns that can be resolved while collaborating with other members. Therefore, joint action in PM is well suited for symmetrical power alliances and reduces conflict in three ways:

First, being reciprocally dependent, the members are required to contribute to the success of the cooperation, but are also more willing to do so, implying that they will open up and establishing a mutual understanding about individual member's motives, opinions, and know-how [20, 21]. By this, misunderstandings and "mutual feelings of frustration" [68, p. 65] are avoided already early on. The members are enabled to put other members' behavior and actions into context and effectively transmit their own actions [69]. This creates the conditions to clear up possible task-related contradictions [20, 21].

Second, joint action leads to relational norms and mutual trust among members [70]. These act as a safeguard against partner misbehavior, improve coordination and reduce exchange hazards [71]. Here, exchanges in an alliance are embedded within a system of relational norms and social interactions which create mutual confidence that no party will exploit others' vulnerabilities even if there is such opportunity [72]. Further, member involvement and the corresponding collaboration increase commitment and ownership. As the companies feel that their voice and contribution to directly address points of concern at a rather early stage is valued, their motivation is increased, helping minimize the risk that dissent manifests into conflicts [22, 69]. 
Third, acting jointly in PM strengthens interpersonal relations $[22,73]$ that leads to a benevolent atmosphere and helps establishing pride for being a member of the alliance $[74,75]$. Strong interpersonal ties and pride in the alliance will facilitate internal cohesion (i.e., an esprit de corps), a sense of belonging together, and maintaining their belief into the alliance even when exposed to internal or external challenges. Especially in settings of coopetition, this reduces the risk that the different members will be aggressive toward each other [76], which in turn, reduces potentials for affective conflicts.

\subsubsection{Asymmetrical power alliances}

In general, according to RDT, companies should choose the least constraining device to govern relations with their exchange partners that will secure resource access and maximize autonomy [45]. Here, asymmetrical power alliances assemble a heterogeneous set of LSPs in the sense that LSPs with a stronger dependence on the alliance, which have given up more autonomy, are combined with others with a weaker dependence that have given up less autonomy to secure their desired resources via the alliance. For the LSPs with more autonomy (and more power), joint action in PM, which implies stronger ties and more coordination, would result in added constraints and reduce both their autonomy and their power advantage over the other members. This would run counter to them striving to keep both their power advantage and their autonomy [25], and creates tension.

As they do not have the same reliance on the alliance, they are more likely to pursue their own agenda [48] and will not be interested in incorporating processes that allow weaker parties detailed insights into the stronger parties' management [48, 49]. Further, they tend to consider themselves to be in power, try "calling the shots" and in that sense dominate processes in the cooperation [50]also PM processes. Applying joint action in PM in this setting would create tension from the RDT perspective between their striving for autonomy and how their autonomy would tend to be restraint by the joint action.

Applying joint action in PM in this setting would also create severe tension from the SCT perspective between the actual power situation and the expectations that would be created for the less powerful members via joint action. As outlined before, joint action entails close collaboration and mutuality, and promotes an atmosphere of forbearance, mutual respect, and balanced reciprocity. Further, it implies interacting on equal footing, where all members contribute to and influence the outcome to similar degrees. As a consequence, joint action in PM would create a social contract of mutual influence that is in contradiction to how the parties view and approach the alliance. Hence, strong collaboration via joint action in a context in which, due to the imbalanced distribution of power, the alliance members are not acting fully on par is not effective and creates tension. Instead, this is likely to be a source of conflict in itself.

Overall, aggregating the negative effects of joint action in PM in an asymmetrical setting and its positive effects in a symmetrical setting, it can be concluded that joint action in PM is effective in reducing conflict in symmetrical power settings and that it will be less effective the more asymmetrical the alliance is. This will be the case for both affective and cognitive conflicts because joint action addresses both levels of these conflicts: the task-related level of cognitive conflict as well as the personal level of affective conflict. Thus, we hypothesize:

$\mathbf{H}_{\mathbf{1} \mathbf{a}, \mathbf{b}}$ Joint action in PM is more effective in reducing a) affective and b) cognitive conflict in horizontal alliances with symmetrical power relation than in ones with asymmetrical power relation.

\subsection{Context-dependent effectiveness of information sharing in PM}

Information sharing with respect to PM refers to sharing important information regarding the process as well as the results of PM (i.e., values attained for the performance indicators). Such information sharing has been found to be vital $[19,20]$ as it facilitates transparency with regard to performance. Through "communication [...] task details, task progress, and reasoning for task decisions" [20, p. 384] are clarified. The alliance members are better able to understand other members' way of thinking, minimizing animosities and misinterpretations that could lead to both affective and cognitive conflicts. This helps reducing the level of uncertainty [77] and creating a common understanding [59], which improves coordination [78] and reduces the level of conflict [20]. Additionally, problems can proactively be prevented as more thorough decisions can be made [79]. This reduces the risk of errors, which, in turn, is associated with less conflict about task-related issues [20].

Yet, in comparison to joint action in PM, the extent and intensity of exchange is substantially smaller as information sharing focuses on informing alliance members about issues and results of PM and not integrating them into PM. It is less comprehensive in providing insights and a common understanding. Moreover, members merely receiving information from other members cannot rule out that the information provided is filtered or even falsified [80]. In the case of joint action, this situation is different as close collaboration increases the ability for verification and reduces risks of misinformation. Thus, information sharing 
is not as effective as joint action in establishing relational norms and trust and in serving as effective means for coordination and mitigating exchange hazards. Consequently, information sharing can be considered a "light" version of collaboration compared to joint action.

Thus, in alliances with symmetrical power relation, information sharing has only little or even nothing to add to the potentials created via joint action in PM, and thus, joint action will be substantially more effective in mitigating conflict in this context.

In contrast, when power is unevenly distributed, the less dependent members are less interested in giving up autonomy by establishing extensive collaborative processes as "constant coordination and mutual adjustment among group members is not necessary for the group to function successfully" [20, p. 390]. Because joint action in PM is not in the interest of the less dependent members, these alliances can instead only rely on information sharing in PM, which constitutes a less pronounced form of collaboration to mitigate conflict. From the SCT perspective, this approach entails social contracts that differ from those of joint action in the sense that it allows for one or a few parties to dominate decisions on what and how much information is exchanged. In that sense, information sharing is compatible with companies wanting to dominate, while still providing potential to prevent conflict from manifesting itself.

Consequently, information sharing in PM is an effective approach to reduce affective and cognitive conflicts in alliances with asymmetrical power relations, whereas in symmetrical power relations this is not the case:

$\mathbf{H}_{2 \mathbf{a}, \mathbf{b}}$ Information sharing in PM is more effective in reducing a) affective and b) cognitive conflict in horizontal alliances with asymmetrical power relation than in ones with symmetrical power relation.

\section{Methodology}

\subsection{Sampling and data collection}

For testing the hypotheses, primary data from LSPs were collected. We employed a key informant approach [81] and targeted senior managers of the LSPs to provide information regarding one horizontal LSP alliance they were active in (here relationships with a subcontracting nature where explicitly highlighted to be out of the scope of the survey). The executive management level was chosen as appropriate point of contact due to the rather small company size in the industry and in the sample (50\% of the surveyed LSPs have less than 100 employees-see Table 1) and the fact that the executive managers at LSPs are still involved even
Table 1 Demographics of responding companies

\begin{tabular}{lrr}
\hline Annual turnover (in $€$ ) & $N$ & $\%$ \\
\hline $1-5$ million & 51 & 26 \\
$>5-25$ million & 57 & 30 \\
$>25-100$ million & 37 & 19 \\
$>100-500$ million & 22 & 11 \\
$>500$ million-5 billion & 9 & 5 \\
$>5$ billion & 2 & 1 \\
Not specified & 15 & 8 \\
Total & 193 & 100 \\
\hline Number of employees & $N$ & $\%$ \\
\hline $1-50$ & 64 & 33 \\
$51-100$ & 31 & 16 \\
$101-500$ & 44 & 23 \\
$501-1000$ & 20 & 10 \\
$>1000$ & 22 & 12 \\
Not specified & 12 & 100 \\
Total & 193 & \\
\hline
\end{tabular}

at the day-to-day level of cooperating with other LSPs in a horizontal alliance.

We derived the sample from two commercial databases that provide company data of German LSPs with annual revenue of more than $€ 1$ million. The executive managers received an email invitation with a personalized link to our web-based survey in German language. Overall, a response rate of $11.7 \%$ was achieved. After discarding 18 responses due to incomplete data and four responses because they represented outliers as identified based on Mahalanobis distance, 193 usable responses remained for the analyses (see Table 1).

We followed established practices for testing non-response bias. First, answers of early and late responders were compared [82]. Second, a follow-up study was conducted with 18 randomly chosen non-respondents, who received a questionnaire with 12 items of the original survey [83]. Their responses were compared to the ones of the participants that completed the questionnaire in the first place. Neither method indicated significant differences in the data.

\subsection{Measurement scales}

For the constructs of the present hypothesized model, we used previously established measurement scales and adapted them to the current study. A qualitative pretest with ten logistics researchers and seven CEOs of LSPs was carried out to ensure face validity. In this process, few minor alterations were made iteratively to the construct 
measurements until no further changes were suggested. The measurement of the constructs relied on multi-item, 7-point Likert-type scales presented in the Appendix 1 and described in the following.

Joint action in PM was measured based on [64] and refers to the extent to which PM activities are integrated via coordination across alliance members. Information sharing in $P M$ was captured based on the scale of [84] and refers to the extent to which the alliance members keep each other informed about critical and proprietary information concerning PM. Cognitive conflict and affective conflict were measured based on [33]. The construct for cognitive conflict measures the extent to which task oriented conflicts were experienced, whereas the construct for affective conflict identifies the extent to which emotional and personal incompatibilities or disputes were experienced.

To capture the power structure, we used two scales of [85]. The firms' dependence on the alliance was assessed by measuring to what extent the alliance was important to them. The alliance's dependency on the individual firm was measured by asking for the extent to which the respondent's company is important for the alliance. For the multigroup analysis, the sample was divided into two groups based on the power structure that was calculated as the absolute difference between the average score of the items of the first construct and the average score of the items of the second construct. Values up to 0.75 were considered as symmetrical power relation $(N=72)$ as the respondents' company depends on the cooperation to a similar degree to that the cooperation depends on it. Values above 0.75 were considered as asymmetrical power relation $(N=121)$. The rationale behind this cutoff was that if the majority of items differed by at least one between the two constructs, the relation would be considered asymmetrical. To ensure robustness, we also tested a cutoff of 1.0 with two groups of $N=84$ and $N=109$; the results of this model were consistent with those of the 0.75 cutoff that will be reported below in the Results section.

To validate the measurement scales, we conducted an exploratory factor analysis using SPSS, extracting four factors equivalent to our four focal constructs (see Appendix 2). Subsequently, we conducted a confirmatory factor analysis with AMOS to assess the reliability and validity of the measurement model, which revealed adequate fit $\left(\chi^{2}=173.0 \quad\right.$ with $\quad d f=81 ; \quad \chi^{2} / d f=2.14$; $\mathrm{CFI}=0.96$; RMSEA $=0.077$ ). All factor loadings were significant at $p<0.001$, supporting convergent validity for the constructs. Item reliability exceeded 0.4 for all items. The lowest Cronbach's alpha and the lowest composite reliability for the latent constructs are 0.86 (see Appendix
1). Additionally, [86] procedure to test discriminant validity was used. The squared correlations between any pair of the four constructs used were lower than the average variance extracted of the corresponding constructs (see Appendix 3).

\subsection{Control variables}

We aimed to control for cooperation size [87] and relationship duration [88]. The first variable captures the number of companies engaged in the alliance, whereas the second variable captures the number of years the alliance exists. This is intended to account for any influence that the two variables may have on affective and cognitive conflicts. During normality tests, these two variables exhibited a relatively strong positive skew. Therefore, a square-root-transformation on the original data was performed and, subsequently, the square root of cooperation size and of relationship duration was used as control variables.

\subsection{Results}

The structural equations model was tested by conducting a multi-group analysis using AMOS to identify the moderating effects of the power structure. The fit indices showed adequate model fit for the hypothesized model $\left(\chi^{2}=323.0\right.$ with $d f=210 ; \quad \chi^{2} / d f=1.54 ; \quad$ CFI $=0.95 ; \quad$ RMSEA $=0.05$ ). Table 2 presents the results of the hypothesized relationships.

Hypotheses $\mathrm{H}_{1 \mathrm{a}, \mathrm{b}}$, which postulate that joint action in PM is more effective in reducing both forms of conflict in symmetrical power relations than in asymmetrical ones, are supported. In symmetrical power relations, joint action has a significant negative effect on affective conflict $(-0.372$; $p<0.05)$ and on cognitive conflict $(-0.533 ; p<0.01)$. In contrast, it has no significant effect in asymmetrical power relations, neither on affective conflict $(0.178$; n.s.), nor on cognitive conflict $(-0.122$; n.s.). The differences between symmetrical and asymmetrical power structures are significant for both paths.

Hypotheses $\mathrm{H} 2_{\mathrm{a}, \mathrm{b}}$ posit that information sharing in $\mathrm{PM}$ is more effective in reducing conflict in asymmetrical power relations than in symmetrical ones. Our results fully support hypothesis $\mathrm{H}_{2 \mathrm{a}}$ : Information sharing in $\mathrm{PM}$ has a significant negative effect on affective conflict in asymmetrical power relations $(-0.455 ; p<0.01)$, whereas the effect in a symmetrical power relation is nonsignificant $(+0.078$; n.s. $)$. Furthermore, the structural paths are significantly different $(p<0.01)$. At the same time, the effect of information sharing in PM on cognitive conflict in 
Table 2 Results of multi-group analysis with respect to power structure (unstandardized path coefficients)

\begin{tabular}{|c|c|c|c|c|c|c|c|}
\hline & \multicolumn{4}{|c|}{ Power structure } & & & \multirow[t]{3}{*}{ Hypothesis } \\
\hline & \multicolumn{2}{|c|}{ Symmetrical } & \multicolumn{2}{|c|}{ Asymmetrical } & \multicolumn{2}{|c|}{ Difference } & \\
\hline & Estimate & $p$ & Estimate & $p$ & $z$-score & $p$ & \\
\hline Joint action $\rightarrow$ affective conflict (H1a) & -0.372 & 0.045 & 0.178 & 0.334 & 2.091 & 0.018 & Support \\
\hline Joint action $\rightarrow$ cognitive conflict (H1b) & $-\mathbf{0 . 5 3 3}$ & 0.003 & -0.122 & 0.525 & 1.599 & 0.055 & Support \\
\hline Information sharing $\rightarrow$ affective conflict (H2a) & 0.078 & 0.620 & -0.455 & 0.002 & -2.471 & 0.007 & Support \\
\hline Information sharing $\rightarrow$ cognitive conflict $(\mathrm{H} 2 \mathrm{~b})$ & 0.082 & 0.554 & -0.225 & 0.134 & -1.499 & 0.067 & Weak support \\
\hline$R^{2}$ affective conflict & $12.6 \%$ & & $20.8 \%$ & & & & \\
\hline$R^{2}$ cognitive conflict & $29.6 \%$ & & $12.2 \%$ & & & & \\
\hline
\end{tabular}

Bold values indicate significant relationships

symmetrical power relations is also negative, but above the significance threshold $(-0.225 ; p=0.134)$. But again, the moderation follows the hypothesized pattern (i.e., information sharing is more effective in asymmetrical power relations), and this difference is significant ( $p=0.067)$, so that weak support for $\mathrm{H}_{2 \mathrm{~b}}$ can be concluded.

Further, our results show that the explanatory power of the two collaborative processes is substantial for symmetrical power relations; the $R^{2}$ is $12.6 \%$ for affective conflict and $29.6 \%$ for cognitive conflict. In asymmetrical power relations, collaborative processes in PM account for a little lower but still substantial percentage of variance in conflict ( $R^{2}=20.8 \%$ for affective conflict and $R^{2}=12.2 \%$ for cognitive conflict) (see Table 2 ). With regards to our control variables, we find that neither the square root of cooperation size, nor of relationship duration has a significant effect on affective and cognitive conflicts (all $p$ values are above 0.4 ).

\section{Discussion and implications}

\subsection{Theoretical implications}

The results of this study present several important theoretical implications with respect to conflict in horizontal alliances. Even though conflict has been studied extensively in prior research (e.g., [10, 11, 33]), the focus, so far, was mainly on post-manifestation topics such as conflict management, neglecting that conflict could be prevented before emerging in the first place. The major drawback of the prior research that actually was concerned with conflict prevention is that it mostly builds on antecedents of conflict that are not really actionable, for example, the similarity of organizational climate [62] or goal uncertainty [38]. Exceptions are the studies of [20], who tested the effect of information sharing in student groups and its effect on conflict and performance, and [18] who presented a model of proactive approaches for handling conflicts such as selecting partner fit, partnership negotiation, and the build up of relational quality among members in international joint ventures. Here, our research provides one additional step by focussing on actionable collaborative processes (i.e., joint action and information sharing) in a concrete environment (i.e., PM) that can be applied to contribute to a reduction of the overall levels of affective and cognitive conflicts within a horizontal cooperation. This, at the same time, underscores that collaboration is an approach to improve the performance of supply chain relationships [89], and that PM is of key importance to horizontal alliances in that it not only is an area prone to conflict, but also one with the potential to mitigate conflict.

To further refine our assertions, we applied a contextspecific view based on RDT and SCT focussing on autonomy of the involved LSPs and the social contracts embedded in the alliance. Here, our findings first underscore the prior assumption that how conflict emerges and manifests itself depends on the context [21, 22] and that the power structure within the cooperation is a relevant contextual variable [21, 24, 28].

Second, prior findings are expanded in showing that the effectiveness of collaboration is not equal for symmetrical and asymmetrical power relations. Overall, collaborative processes in PM are effective in preventing conflict in both setups. Yet, joint action is most effective in symmetrical power relations, while information sharing is most effective in asymmetrical power relations. Conducting a mutual approach such as joint action usually is based on alliance members that all give up autonomy in the alliance and are reciprocally dependent and hence interested in maintaining or even intensifying a close relationship [48]. Otherwise they would not be willing to both give and take in the 
relationship as well as provide insights into their motives, opinions, and know-how [48, 49]. Prior expectations were that information sharing is rather effective in mitigating the risk of conflict manifestation in asymmetrical power relations as in such a situation, the more powerful members are less interested in reducing their autonomy and altering social contracts by establishing processes that are involving in nature [20]. In this case, stronger members rather prefer information sharing where they can better steer which information is disclosed. Our results were able to support this. Thus, we show with our research that the suitability as well as the effectiveness of collaborative processes is very much dependent on the context (in this case, the power structure) in which they are applied.

\subsection{Managerial implications}

The results of our study are of importance to practice in that they provide guidance to managing horizontal alliances in particular. Our research provides managers with insights on how to prevent conflict potential to manifest itself in actual conflict.

The first important aspect is that managers need to shift their focus of attention from post-manifestation issues of conflict (i.e., conflict management techniques after the conflict has already emerged) to the question of how conflict can proactively be prevented. If conflict has already emerged, it is difficult to control [63] and necessitates considerable effort to manage and resolve it [10, 43, 62]. In this respect, the present research found that PM is an area where conflicts can emerge, because within this area different viewpoints and approaches meet and clash.

Building on this, the results show that PM, besides being a potential source of conflict, can also be utilized to remedy this issue and to reduce the overall level of conflict-both cognitive and affective-in an alliance. Keys to this are processes such as joint action and information sharing in $\mathrm{PM}$, and such collaborative process can already be initiated at the start of the alliance via contractual provisions [90]. However, their effectiveness to proactively prevent the manifestation of conflict is highly dependent on the specific context of the cooperation and specifically the inherent power structure. In symmetrical power relations, where members are cooperating on equal footing, managers should focus on high participation and involvement during the PM. This does not further impede the autonomy of the alliance members and is consistent with the underlying social contracts of the cooperation. This situation is very different in asymmetrical power relation settings. Here, where dependency and autonomy across alliance members are unequally distributed, instead increased transparency through information sharing is effective while joint action of the alliance members is not effective in mitigating conflict as it reduces member autonomy and runs counter to the implicit social contracts of the alliance.

Thus, managers should be aware of the fact that, first, their focus should be on proactive rather than reactive measures and, second, that when taking measures these have to be chosen depending on the contextual situation they find themselves in.

\section{Limitations and further research}

In sum, this article provides sound results regarding conflict prevention in horizontal alliances in general and of LSPs in particular. However, the qualification of our conclusions necessitates an acknowledgment of limitations inherent to this study.

First, the study focus was on horizontal cooperation. Compared to vertical relationships, the mode of collaboration in horizontal alliances differs due to their often multilateral setup [3]. This complicates collaborative processes as more than two companies are to be included. Thus, due to the more straightforward arrangement of a buyer-supplier relationship in vertical settings, the effectiveness of the different collaborative processes in PM may be even more pronounced. In order to examine potential differences in the effectiveness, we encourage the replication of our study for vertical relationships. Second, this study used data from the logistics industry. This is an industry in which fear of competition is high while at the same time utilizing horizontal cooperation is very common. Therefore, we expect the conflict-reducing potential of collaborative process to be higher than in other industries, while we do not expect any differences in the underlying general mechanisms of conflict prevention. To investigate potential differences to other service industries, corresponding research is encouraged. Last, we limit our consideration to PM. We also suggest testing the role of joint action and information sharing in other areas of horizontal cooperation. Here, it could be promising to also view less central activities to view how conflict in peripheral areas may also infect collaboration in central activities. $^{2}$

Open Access This article is distributed under the terms of the Creative Commons Attribution 4.0 International License (http://crea tivecommons.org/licenses/by/4.0/), which permits unrestricted use, distribution, and reproduction in any medium, provided you give appropriate credit to the original author(s) and the source, provide a link to the Creative Commons license, and indicate if changes were made.

\footnotetext{
$\overline{2}$ We thank one anonymous reviewer for providing the idea for this promising future research.
} 


\section{Appendix 1}

See Table 3.

Table 3 Constructs and questionnaire scale items

Measurement scales

Mean SD

Joint action in $\mathbf{P M}^{\mathrm{a}}$ [64]

Cronbach's alpha $=0.87 ;$ Composite reliability $=0.86 ; \mathrm{AVE}=0.61$

Joint action 1: Our performance measurement activities across the cooperation are well coordinated

$4.46 \quad 1.86$

Joint action 2: We systematically coordinate our performance measurement strategies with our cooperation partners

$4.12 \quad 1.91$

Joint action 3: We have processes to systematically transfer performance measurement knowledge across the cooperation partners

$4.63 \quad 1.75$

Joint action 4: Managers from different cooperation members meet periodically to examine how we can create synergies with $4.44 \quad 1.80$

respect to performance measurement across our cooperation

Information sharing in $\mathbf{P M}^{\mathrm{a}}$ [84]

Cronbach's alpha $=0.92 ;$ Composite reliability $=0.91 ; \mathrm{AVE}=0.73$

Inf. sharing 1: We share our results of the cooperation performance measurement with our cooperation partners

Inf. sharing 2: Our cooperation partners share proprietary performance measurement results with us

Inf. sharing 3: We inform our cooperation partners in advance of changing needs concerning the cooperation performance

measurement

Inf. sharing 4: In our cooperation it is common that partners are informed concerning occurrences and changes with respect to performance measurement

The cooperation partners keep us fully informed about performance measurement issues (e.g., goal deviations) (eliminated in scale refinement process)

\section{Affective conflict ${ }^{\mathrm{a}}$ [33]}

Cronbach's alpha $=0.86$; composite reliability $=0.86 ; \mathrm{AVE}=0.68$

When taking joint decisions ...

Affec. conflict $1: \ldots$ there is tension in the cooperation decision-making process

Affec. conflict 1: ... we and our cooperation partners often come into conflict due to different personalities

Affec. conflict 3: ... personal dislikes transform objective discussions into emotional conflicts.

... there often is disagreement in the cooperation concerning the results (eliminated in scale refinement process)

Cognitive conflict ${ }^{\mathrm{a}}$ [33]

Cronbach's alpha $=0.92 ;$ composite reliability $=0.91 ; \mathrm{AVE}=0.72$

The cooperation is characterized that we and our cooperation partners ...

Cogn. conflict 1: ... have often disagreements over questions of content

Cogn. conflict 2: ... have often to work through differences about the content of tasks

Cogn. conflict 3: ... have often differences in opinions

Cogn. conflict 4: ... have often different opinions concerning methods for problem resolution (new item)

Dependence of focal firm on alliance ${ }^{\mathrm{a}}$ [85]

Cronbach's alpha $=0.90$

If our relationship was discontinued with this cooperation, we would have difficulty in keeping up our current business

This cooperation is crucial to our future performance

We are dependent on this cooperation

This cooperation is essential to round out our service offering

If our relationship was discontinued, we would have difficulty in replacing this cooperation

Dependence of alliance on focal firm ${ }^{\mathrm{a}}[85]$

Cronbach's alpha $=0.88$

If we discontinued being a member of this cooperation, this cooperation would have difficulty in keeping up business

We are important to this cooperation

We play a major role in contributing to the success of this cooperation

We are difficult to replace in this cooperation (new item) 
Table 3 continued

\begin{tabular}{lll}
\hline Control variables & Mean & \\
\hline Relationship duration [88] & 11.44 & \\
Since how many years does this cooperation exist? & & \\
Alliance size [87] & $N$ & \\
How many companies are engaged in the cooperation? & 35 & \\
2 & 60 & \\
$3-10$ & 23 & \\
$11-20$ & 18 & \\
$21-50$ & 29 & 12 \\
$51-100$ & 23 & 10 \\
$>100$ & 2 & 12 \\
Not specified & 4 & 2 \\
\hline
\end{tabular}

${ }^{a}$ Corresponding items are measured on a 7-point Likert scale anchored by $1=$ strongly disagree and $7=$ strongly agree

\section{Appendix 2}

See Table 4.

Table 4 Exploratory factor analysis

\begin{tabular}{lcccc}
\hline Items $^{\text {a }}$ & Joint action & Inf. sharing & Affec. conflict & Cogn. conflict \\
\hline Joint action 1 & $\mathbf{0 . 8 2 5}$ & 0.058 & 0.082 & -0.006 \\
Joint action 2 & $\mathbf{0 . 8 1 9}$ & 0.135 & 0.121 & -0.003 \\
Joint action 3 & $\mathbf{0 . 8 6 2}$ & 0.008 & -0.102 & 0.076 \\
Joint action 4 & $\mathbf{0 . 8 4 9}$ & -0.110 & -0.033 & -0.033 \\
Inf. sharing 1 & -0.023 & $\mathbf{0 . 9 6 1}$ & 0.071 & 0.025 \\
Inf. sharing 2 & -0.046 & $\mathbf{0 . 9 5 9}$ & 0.028 & -0.008 \\
Inf. sharing 3 & 0.043 & $\mathbf{0 . 8 5 2}$ & -0.074 & -0.023 \\
Inf. sharing 4 & 0.109 & $\mathbf{0 . 7 2 3}$ & -0.112 & -0.027 \\
Affec. conflict 1 & -0.120 & 0.082 & $\mathbf{0 . 6 1 8}$ & 0.326 \\
Affec. conflict 2 & 0.056 & 0.020 & $\mathbf{0 . 9 4 8}$ & -0.011 \\
Affec. conflict 3 & 0.034 & -0.086 & $\mathbf{0 . 9 2 5}$ & -0.071 \\
Cogn. conflict 1 & 0.037 & -0.039 & 0.081 & $\mathbf{0 . 8 3 3}$ \\
Cogn. conflict 2 & -0.088 & 0.030 & -0.001 & $\mathbf{0 . 8 7 5}$ \\
Cogn. conflict 3 & 0.040 & -0.045 & -0.071 & $\mathbf{0 . 9 6 3}$ \\
Cogn. conflict 4 & 0.049 & 0.017 & -0.046 & $\mathbf{0 . 9 3 3}$ \\
AVE & 0.61 & 0.73 & 0.68 & 0.72 \\
CR & 0.86 & 0.91 & 0.86 & 0.91 \\
\hline Standardzed fas & & &
\end{tabular}

Standardized factor loadings, average variance extracted, and composite reliabilities of the latent variables Standardized factor loadings above 0.6 are denoted in bold

${ }^{\text {a }}$ Joint action = joint action in PM; inf. sharing = information sharing in PM; affec. conflict = affective conflict; cogn. conflict $=$ cognitive conflict 


\section{Appendix 3}

\section{See Table 5.}

Table 5 Comparison of AVE and squared correlations (FornellLarcker criterion)

\begin{tabular}{lllll}
\hline & $(1)$ & $(2)$ & (3) & (4) \\
\hline (1) Joint action in PM & 0.61 & & & \\
(2) Information sharing in PM & 0.43 & 0.73 & & \\
(3) Affective conflict & 0.07 & 0.06 & 0.68 & \\
(4) Cognitive conflict & 0.12 & 0.06 & 0.55 & 0.72
\end{tabular}

Values on the diagonal are estimates of average variance extracted (AVE), and values below the diagonal are the squared correlations between the constructs

\section{References}

1. Cruijssen F, Cools M, Dullaert W (2007) Horizontal cooperation in logistics: opportunities and impediments. Transp Res E Log 43(2):129-142

2. Pomponi F, Fratocchi L, Tafuri SR (2015) Trust development and horizontal collaboration in logistics: a theory based evolutionary framework. Supply Chain Manag 20(1):83-97

3. Schmoltzi C, Wallenburg CM (2011) Horizontal cooperations between logistics service providers: motives, structure, performance. Int J Phys Distrib 41(6):552-575

4. Carbone V, Stone MA (2005) Growth and relational strategies used by the European logistics service providers: rationale and outcomes. Transp Res E Log 41(6):495-510

5. Schmoltzi C, Wallenburg CM (2012) Operational governance in horizontal cooperations of logistics service providers: performance effects and the moderating role of cooperation complexity. J Supply Chain Manag 48(2):53-74

6. Bengtsson M, Kock S (2014) Coopetition-Quo vadis? Past accomplishments and future challenges. Ind Mark Manag 43(2): $180-188$

7. Wild N, Zhou L (2011) Ethical procurement strategies for international aid non-government organisations. Supply Chain Manag 16(2):110-127

8. Christoffersen J (2013) A review of antecedents of international strategic alliance performance: synthesized evidence and new directions for core constructs. Int J Manag Rev 15(1):66-85

9. Parayitam S, Dooley RS (2011) Is too much cognitive conflict in strategic decision-making teams too bad? Int J Confl Manag 22(4):342-357

10. Parry ME, Song M, Spekman RE (2008) Task conflict, integrative potential and conflict management strategies in joint ventures. IEEE Trans Eng Manag 55(2):201-218

11. Rahim MA (2002) Toward a theory of managing organizational conflict. Int J Confl Manag 13(3):206-235

12. Das TK, Teng BS (2003) Partner analysis and alliance performance. Scan J Manag 19(3):279-308

13. Janowicz-Panjaitan M, Krishnan R (2009) Measures for dealing with competence and integrity violations of interorganizational trust at the corporate and operating levels of organizational hierarchy. J Manag Stud 46(2):245-268

14. Bititci US, Carrie AS, McDevitt L (1997) Integrated performance measurement systems: a development guide. Int J Oper Prod Manag 17(5):522-534
15. Melnyk SA, Bititci U, Platts K, Tobias J, Andersen B (2014) Is performance measurement and management fit for the future? Manag Acc Res 25(2):173-186

16. Forslund H (2012) Performance management in supply chains: logistics service providers' perspective. Int J Phys Distrib 42(3):296-311

17. Forslund H, Jonsson P (2007) Dyadic integration of the performance management process: a delivery service case study. Int $\mathrm{J}$ Phys Distrib 37(7):546-567

18. Le Nguyen H (2011) Partnership strategies: pro-active and preactive approach in conflict management in international joint ventures. Int J Bus Manag 6(9):38-45

19. Korsgaard MA, Jeong SS, Mahony DM, Pitariu AH (2008) A multilevel view of intragroup conflict. J Manag 34(6):1222-1252

20. Moye NA, Langfred CW (2004) Information sharing and group conflict: going beyond decision making to understand the effects of information sharing on performance. Int $\mathrm{J}$ Confl Manag 15(4):381-410

21. Vaaland T, Håkansson H (2003) Exploring interorganizational conflict in complex projects. Ind Mark Manag 32(2):127-138

22. Wall JA, Callister RR (1995) Conflict and its management. J Manag 21(3):515-558

23. Nyaga GN, Lynch DF, Marshall D, Ambrose E (2013) Power asymmetry, adaptation and collaboration in dyadic relationships involving a powerful partner. J Supply Chain Manag 49(3):42-65

24. Tjosvold D, Cho YH, Park HH, Liu C, Liu WC, Sasaki S (2001) Interdependence and managing conflict with sub-contractors in the construction industry in East Asia. Asia Pac J Manag 18(3):295-313

25. Pfeffer J, Salancik GR (1978) The external control of organizations: a resource dependence perspective. Harper \& Row, New York

26. Dunfee TW, Smith NC, Ross WT (1999) Contracts and social marketing ethics. J Mark 63(3):14-32

27. Wallenburg CM, Schäffler T (2014) The interplay of relational governance and formal control in horizontal alliances: a social contract perspective. J of Supply Chain Manag 50(2):41-58

28. Dant RP, Schul PL (1992) Conflict resolution processes in contractual channels of distribution. J Mark 56(1):38-54

29. Lin X, Germain R (1998) Sustaining satisfactory joint venture relationships: the role of conflict resolution strategy. J Int Bus Stud 29(1):179-196

30. Stern LW, Reve T (1980) Distribution channels as political economies: a framework for comparative analysis. J Mark 44(3):52-64

31. Das TK, Teng BS (2000) Instabilities of strategic alliances: an internal tensions perspective. Organ Sci 11(1):77-101

32. Wilhelm MM (2011) Managing coopetition through horizontal supply chain relations: linking dyadic and network levels of analysis. J Oper Manag 29(7-8):663-676

33. Amason AC (1996) Distinguishing the effects of functional and dysfunctional conflict on strategic decision making: resolving a paradox for top management teams. Acad Manag J 39(1):123-148

34. De Dreu CKW, Weingart LR (2003) Task versus relationship conflict, team effectiveness and team member satisfaction: a meta-analysis. J Appl Psychol 88(4):741-749

35. Jehn KA (1997) A qualitative analysis of conflict types and dimensions in organizational groups. Adm Sci Q 42:530-557

36. Jehn KA, Greer L, Levine S, Szulanski G (2008) The effects of conflict types, dimensions, and emergent states on group outcomes. Group Decis Negot 17(6):465-495

37. Das TK, Kumar R (2010) Interpretive schemes in cross-national alliances: managing conflicts and discrepancies. Cross Cult Manag Int J 17(2):154-169 
38. Mooney AC, Holahan PJ, Amason AC (2007) Don't take it personally: exploring cognitive conflict as a mediator of affective conflict. J Manag Stud 44(5):733-758

39. Deutsch M (1969) Conflicts: productive and destructive. J Soc Issues 25(1):7-42

40. Andrade L, Plowman DA, Duchon D (2008) Getting past conflict resolution: a complexity view of conflict. Emerg Complex Organ 10(1):41-48

41. Jehn KA (1997) Affective and cognitive conflict in work groups: increasing performance through value-based intragroup conflict. In: De Dreu CKW, Van de Vliert E (eds) Using conflict in organizations. Sage, Thousand Oaks, pp 87-100

42. Hall RH (1972) Organization, structure and process. Prentice Hall, Englewood Cliffs

43. Wallenburg CM, Raue JS (2011) Conflict and its governance in horizontal cooperations of logistics service providers. Int J Phys Distrib 41(4):385-400

44. Claycomb C, Frankwick GL (2004) A contingency perspective of communication, conflict resolution and buyer search effort in buyer-supplier relationships. J Supply Chain Manag 40(1):18-34

45. Davis G, Cobb JA (2010) Chapter 2 resource dependence theory: past and future. In: Schoonhoven CB, Dobbin F (eds) Stanford's organization: theory renaissance 1970-2000 (Research in the sociology of organizations, vol 28). Emerald Group Publishing Limited, pp 21-42

46. Heide JB, Wathne KH, Rokkan AI (2007) Interfirm monitoring, social contracts, and relationship outcomes. J Mark Res 44(3):425-433

47. Edwards JC, Karau SJ (2007) Psychological contract or social contract? development of the employment contracts scale. J Lead Organ Stud 13(3):67-78

48. Lusch RF, Brown JR (1996) Interdependency, contracting and relational behavior in marketing channels. J Mark 60(4):19-38

49. Frazier GL (1999) Organizing and managing channels of distribution. J Acad Mark Sci 27(2):226-240

50. Jarratt D, Morrison M (2003) Dependence and the application of power and control in major business relationships: a study of manufacturing and service firms in the business-to-business sector. J Strateg Mark 11(4):235-253

51. Heide JB, John G (1990) Alliances in industrial purchasing: the determinants of joint action in buyer-supplier relationships. J Mark Res 27(1):24-36

52. Aldrich H (2007) Organizations and environments. Stanford University Press, Redwood City

53. Carlsson-Wall M, Kraus K, Messner M (2016) Performance measurement systems and the enactment of different institutional logics: insights from a football organization. Manag Acc Res. doi:10.1016/j.mar.2016.01.006

54. Neely A, Gregory M, Platts K (1995) Performance measurement system design: a literature review and research agenda. Int J Oper Prod Manag 15(4):80-116

55. Wouters M, Wilderom C (2008) Developing performance-measurement systems as enabling formalization: a longitudinal field study of a logistics department. Acc Org Soc 33(4-5):488-516

56. Rey-Marston M, Neely A (2010) Beyond words: testing alignment among inter-organizational performance measures. Meas Bus Excell 14(1):19-27

57. Lohman C, Fortuin L, Wouters M (2004) Designing a performance measurement system: a case study. Eur J Oper Res 156(2):267-286

58. Lai KH, Ngai EWT, Cheng TCE (2002) Measures for evaluating supply chain performance in transport logistics. Transp Res E $\log 38(6): 439-456$

59. Simatupang TM, Wright AC, Sridharan R (2002) The knowledge of coordination for supply chain integration. Bus Process Manag $\mathrm{J}$ $8(3): 289-308$
60. Holmberg S (2000) A systems perspective on supply chain measurements. Int J Phys Distrib 30(10):847-868

61. Stinchcombe A, Heimer CA (1985) Organizational theory and project management. Norwegian University Press, Oslo

62. Fey CF, Beamish PW (2000) Joint venture conflict: the case of russian international joint ventures. Int Bus Rev 9(2):139-162

63. Amason AC, Thompson KR, Hochwarter WA, Harrison AW (1995) Conflict: an important dimension in successful management teams. Organ Dyn 24(2):20-35

64. Bonner J, Kim D, Cavusgil S (2005) Self-perceived strategic network identity and its effects on market performance in alliance relationships. J Bus Res 58(10):1371-1380

65. Kozlowski SWJ, Bell BS (2003) Work groups and teams in organizations. In: Borman WC, Ilgen DR, Klimoski RJ (eds) Handbook of psychology: industrial and organizational psychology. Wiley-Blackwell, New York, pp 412-469

66. Nyaga GN, Whipple JM, Lynch DF (2010) Examining supply chain relationships: do buyer and supplier perspectives on collaborative relationships differ? J Oper Manag 28(2):101-114

67. Kim K (1999) On determinants of joint action in industrial distributor-supplier relationships: beyond economic efficiency. Int $\mathrm{J}$ Res Mark 16(3):217-236

68. Etgar M (1979) Sources and types of intrachannel conflict. J Retail 55(1):61-75

69. Song M, Xie J, Dyer B (2000) Antecedents and consequences of marketing managers' conflict-handling behaviors. J Mark 64(1):50-66

70. Bertelli AM, Smith CR (2010) Relational contracting and network management. J Publ Adm Res Theor 20:i21-i40

71. Lai F, Tian Y, Huo B (2012) Relational governance and opportunism in logistics outsourcing relationships: empirical evidence from China. Int J Prod Res 50(9):2501-2514

72. Kale P, Singh H, Perlmutter H (2000) Learning and protection of proprietary assets in strategic alliances: building relational capital. Strateg Manag J 21(3):217-237

73. Tjosvold MM (1989) A manager's view of applying conflict knowledge. In: Tjosvold D, Johnson DW (eds) Productive conflict management. Team Media, Minneapolis, pp 216-230

74. Menon A, Bharadwaj SG, Howell R (1996) The quality and effectiveness of marketing strategy: effects of functional and dysfunctional conflict in intraorganizational relationships. J Acad Mark Sci 24(4):299-313

75. Rose GM, Shoham A, Neill S, Ruvio A (2007) Manufacturer perceptions of the consequences of task and emotional conflict within domestic channels of distribution. J Bus Res 60(4):296-304

76. Barclay W (1991) Interdepartmental conflict in organizational buying: the impact of the organizational context. J Mark Res 28(2): 145-159

77. Kwon IWG, Suh T (2004) Factors affecting the level of trust and commitment in supply chain relationships. J Supply Chain Manag $40(2): 4-14$

78. Lee HL, So KC, Tang CS (2000) The value of information sharing in a two-level supply chain. Manag Sci 46(5):626-643

79. Stank T, Crum M, Arango M (1999) Benefits of interfirm coordination in food industry supply chains. J Bus Log 20(2):21-41

80. Li S, Lin B (2006) Accessing information sharing and information quality in supply chain management. Decis Support Syst 42(3):1641-1656

81. Phillips L, Bagozzi RP (1986) On measuring organizational properties of distribution channels: methodological issues in the use of key informants. Res Mark 8(1):313-369

82. Wagner SM, Kemmerling R (2010) Handling nonresponse in logistics research. J Bus Log 31(2):357-382

83. Lambert DM, Harrington TC (1990) Measuring nonresponse bias in customer service mail surveys. J Bus Log 11(2):5-25 
84. Mohr J, Spekman RE (1994) Characteristics of partnership success: partnership attributes, communication behavior and conflict resolution techniques. Strateg Manag J 15(2):135-152

85. Ganesan S (1994) Determinants of long-term orientation in buyer-seller relationships. J Mark 58(2):1-19

86. Fornell C, Larcker DF (1981) Evaluating structural equation models with unobservable variables and measurement error. J Mark Res 18(1):39-50

87. Rubin de Celis JC, Lipinski J (2007) R\&D alliances and the effect of experience on innovation: a focus on the semiconductor industry. J Lead Organ Stud 14(1):26-37
88. Schreiner M, Kale P, Corsten D (2009) What really is alliance management capability and how does it impact alliance outcomes and success? Strateg Manag J 30(13):1395-1419

89. Adams FG, Richey RG, Autry CW, Morgan TR, Gabler CB (2014) Supply chain collaboration, integration, and relational technology: how complex operant resources increase performance outcomes. J Bus Log 35(4):299-317

90. Lumineau F, Henderson JE (2012) The influence of relational experience and contractual governance on the negotiation strategy in buyer-supplier disputes. J Oper Manag 30(5):382-395 